\title{
Determination of areal surface-feature coverage in the Beaufort Sea using aircraft video data
}

\author{
Mark A. Tsqhudi, Judith A. Curry, James A. Maslanik \\ Program in Atmospheric and Oceanic Sciences, Department of Aerospace Engineering, University of Colorado, Boulder, CO 80309-0429, U.S.A.
}

\begin{abstract}
The surface-energy budget of the Arctic Ocean depends on the distribution of various sea-ice features that form by both mechanical and thermodynamic processes. Melt ponds, new ice and open water greatly affect the determination of surface albedo. However, even basic measurements of some surface-feature characteristics, such as areal extent of melt ponds, remain rare.

A method has been developed to assess the areal coverage of melt ponds, new ice and open water using video data from the Beaufort and Arctic Storms Experiment (BASE). A downward-looking video camera mounted on the underside of a Hercules C-130 aircraft provided clear images of the surface. Images acquired over multi-year ice on 21 September 1994 were analyzed using a spectral technique to determine the areal coverage of melt ponds, new ice and open water. Statistics from this analysis were then compared to previous field studies and to the Schramm and others (in press) sea-ice model.
\end{abstract}

\section{INTRODUGTION}

Modifications to the surface albedo that result from changes in the snow and ice cover have been hypothesized to create a positive feedback on climate change (Kellogg, 1975), the well-known "snow-ice-albedo" feedback. As surface temperature increases, the areal coverage of snow and ice will decrease, resulting in a lowering of the albedo as the fraction of open water and melt ponds increases. In turn, the lowering of albedo causes more solar radiation to be absorbed, which increases the rate of sea ice and snowmelt, further lowering the albedo and therefore creating a positive feedback.

De Abreu and others (1995), Allison and others (1993), and Perovich and others (1986) measured spectral albedo for various sea-ice-surface types, and found that individual features, such as melt ponds, serve to lower substantially the albedo from typical values relative to pure ice. To assess the surface albedo properly, determination of the areal aggregate of surface features on the ice pack is therefore required.

The purpose of this study was to obtain statistics for icesurface characteristics by analyzing aircraft video data from the Beaufort and Arctic Storms Experiment (BASE). BASE occurred during September and October 1994 in the Beaufort Sea (Curry and others, 1996). A National Center for Atmospheric Research (NCAR) aircraft carried a suite of instruments to observe the evolution of sea-ice characteristics and radiation fluxes during the 1994 autumnal freezing of the Beaufort Sea coastal waters. The relatively snow-free conditions during the first BASE flight permitted visual identification of melt ponds, multi-year pack ice, new ice and open water.

\section{Acquisition and initial screening of image set}

A clear view of the surface was obtained on 21 September 1994 during $2156-2223 \mathrm{~h}$ UTC (0100 h local time) in an area enclosed by $72.1^{\circ} \mathrm{N}, 134.5^{\circ} \mathrm{W}$ and $71.6^{\circ} \mathrm{N}, 135.6^{\circ} \mathrm{W}$. During this flight, multi-year ice contained frozen melt ponds and was relatively snow-free, and new ice had formed in leads. Skies were overcast, and the flight was below cloud level. The surface conditions were thus indicative of the typically extensive cloud-covered regions in the Beaufort Sea.

Visual identification of sea-ice-surface features over multi-year ice was possible using imagery produced by a Sony XC-999/999P video camera that was mounted on the underside of the aircraft to view the surface. The camera had a $4.8 \times 6.4 \mathrm{~mm}$ field of view, creating an image size of $240 \times 320 \mathrm{~m}$ at $300 \mathrm{~m}$ altitude, which is representative of the flight segments analyzed.

Initial screening was performed to eliminate any images with intervening cloud. Images taken near the ice edge that contained large areas of open water were also eliminated from the dataset. Using standard image-analysis software, surface features were manually delineated on the retained images with a polygon creation tool. Once a polygon is closed, the total number of pixels within the feature was computed. Fractional areal coverages of open water, new ice, and melt ponds were visually computed for each image in this fashion. These percentages were then compared to the results of the automated thresholding method discussed below to determine its accuracy.

Table 1 identifies three segments of video-camera images that passed the manual screening. Each segment was taken from continuous unobstructed views of the surface at low altitude. The aircraft reached the edge of the pack ice at the end of segment 3 .

\section{SPECTRAL IDENTIFICATION OF SURFACE FEATURES}

Grenfell and Maykut (1977) showed from field observations that the spectral reflectance of melt ponds is greater in the 
Table 1. Image set used to compute fractional area coverages of sea-ice surface features

\begin{tabular}{ccccc}
\hline $\begin{array}{c}\text { Segment } \\
\text { no. }\end{array}$ & No. images & \multicolumn{2}{c}{ Center } & Altitude \\
& \multicolumn{5}{c}{ Lat. } & Long. \\
& \multicolumn{4}{c}{} \\
\hline 1 & 11 & $72.07 \mathrm{~N}, \quad 134.70 \mathrm{~W}$ & $180-330 \mathrm{~m}$ \\
2 & 18 & $71.80 \mathrm{~N}, \quad 135.25 \mathrm{~W}$ & $180-360 \mathrm{~m}$ \\
3 & 19 & $71.55 \mathrm{~N}, \quad 135.40 \mathrm{~W}$ & $270-350 \mathrm{~m}$ \\
\hline
\end{tabular}

blue part of the spectrum than the red (Fig. 1). The resulting bluish hue that was exhibited by the melt ponds during BASE is apparent on the video during the 21 September 1994 flight (Fig. 2). This image was photographed at $290 \mathrm{~m}$ altitude, resulting in an areal coverage of $232 \times 309 \mathrm{~m}$ and a pixel size of about $0.5 \mathrm{~m}$.

The amplitude contrast between blue and red bands over melt ponds permits the determination of a blue-band minus red-band threshold difference that defines the pond and separates it from the surrounding pack ice. Several images were examined to determine the appropriate threshold values for melt ponds. New ice and open water can also be identified by their relative reflectance, with open water having the lowest value in all bands, and new ice a reflectance higher than open water but less than melt ponds and pack ice. The surface features manifest themselves as graytone differences, except melt ponds, which are the only features observed that can be classified using their color contrast.

All accepted scenes were then processed using the prescribed thresholds to identify spectrally the surface features. A three-point despeckle filter was then applied to each scene. This algorithm replaced the center pixel of a $3 \times 3$ pixel box with the median value for the box, effectively

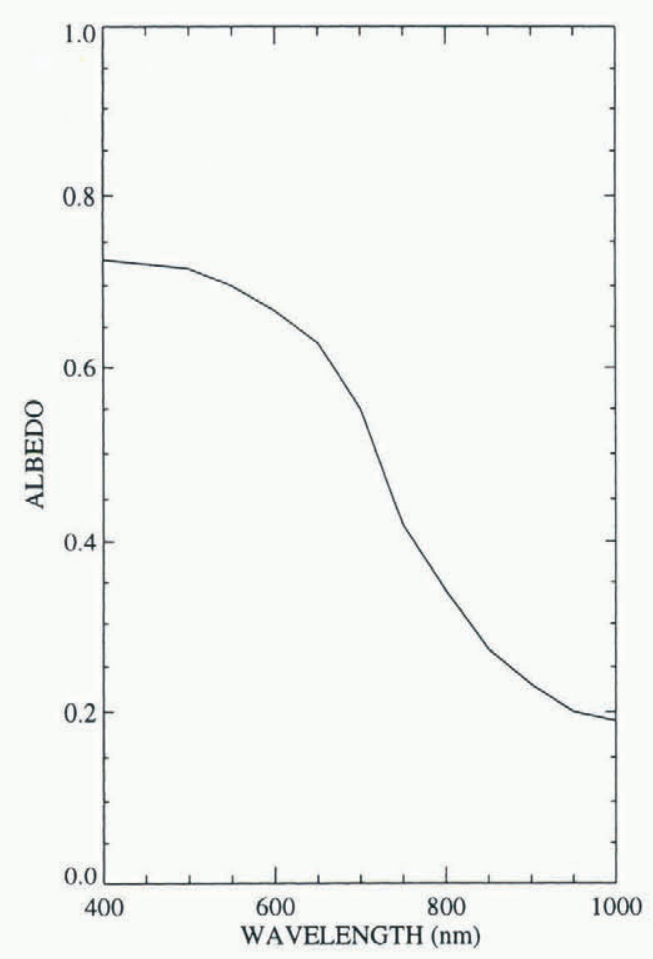

Fig. 1. Spectral albedo observed over partially refrozen melt pond with $3 \mathrm{~cm}$ of ice, overcast. From Grenfell and Maykut (1977).

reducing speckle in each scene. Another program computed the fraction of melt pond, new ice and open water for the scene. The resulting identification of the three surface types is shown in Figure 3, with melt ponds colored red, new ice colored green (on the left side of the image) and open water (to the left of the new ice) colored blue.

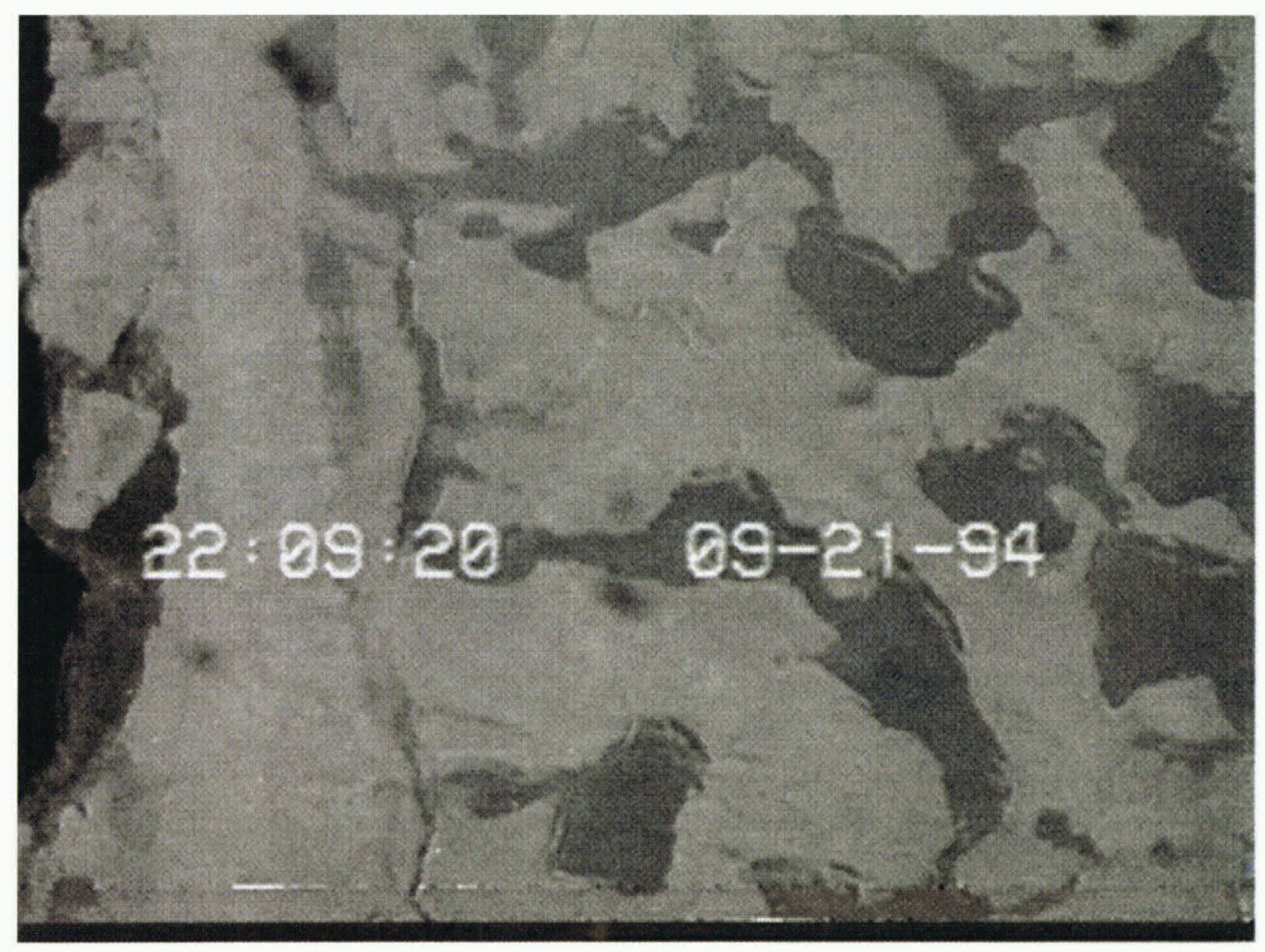

Fig. 2. View of the surface, as videotaped from the underside of a C-130 aircraft during BASE. 


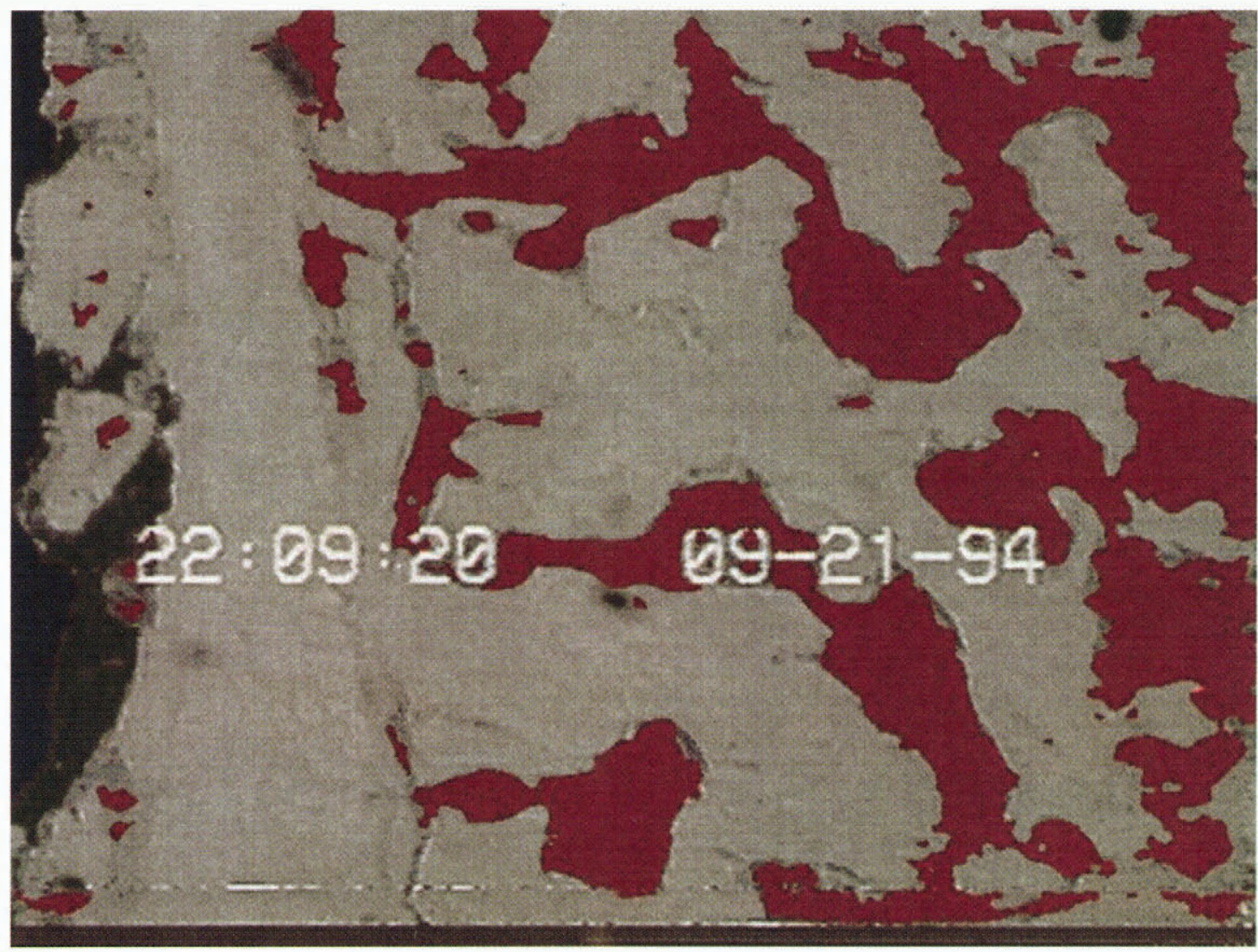

Fig. 3. Spectral identification of frozen melt ponds (red), new ice (blue) and open water (green) after processing Figure 2.

\section{RESULTS AND DISGUSSION}

Table 2 summarizes the results of this spectral technique's application. Manual counts of the individual surface-feature areal coverages in the images showed that the spectral method was accurate to within $1 \%$. The standard deviation for all images is also given (the \pm value), representing the variation in feature areal coverage within the image dataset. In some cases, the spectral method identified small ponds that were obscured by thin clouds and that were initially overlooked during the manual inspection. "New ice" represents ice that had recently formed in leads and between floes.

The total areal coverage of melt ponds is reduced in the presence of leads, since leads occupy a significant portion of the ice pack (Grenfell and Maykut, 1977). In this study, the average melt-pond coverage for all three segments was $23 \pm 6 \%$ for images with no leads and/or broken ice, and $14 \pm 6 \%$ when leads and/or broken ice were present. Lapp (1982) reported an average melt-pond coverage over multiyear ice of $28 \%$ during August 1980 in the Beaufort Sea near

Table 2. Surface-feature areal coverage computed using spectral thresholding. The number of images in each section is given in Table 1

\begin{tabular}{cccc}
\hline Segmentino. & Meltponds & Newice & Openwater \\
& $\%$ & $\%$ & $\%$ \\
\hline 1 & 24 & 2.2 & 0.10 \\
2 & 17 & 4.6 & 0.26 \\
3 & 22 & 7.3 & 0.22 \\
All Images & $20 \pm 8$ & $5.1 \pm 4.3$ & $0.20 \pm 0.43$. \\
\hline
\end{tabular}

$74^{\circ} \mathrm{N}$ and the Canadian Archipelago (about one standard deviation higher than the $20 \%$ value found here for 21 September 1994).

The C-130 aircraft flew to the edge of the pack ice, which marked the end of segment 3. During all segments, melt ponds that had melted through the underlying sea ice were observed, draining the pond of fresh water and refilling it with sea water. The ponds had refrozen, and the hole through the sea ice had a spectral signature similar to new ice in refrozen leads. The perimeter of the pond still exhibited the bluish hue that melt ponds with underlying pack ice possess.

Figure 4 is a view from $272 \mathrm{~m}$ altitude, resulting in an image size of $218 \times 290 \mathrm{~m}$. In this scene, a number of such "melted-through" ponds can be seen. Application of the spectral technique allows detection of the portion of the pond that has penetrated the underlying pack ice and separates it from the remainder of the pond (Fig. 5). Table 3 depicts the effective reduction in the melt-pond areal coverage due to the holes through the pack ice underneath the pond. The percentage of melt-pond holes increase as the

Table 3. Melt-pond morphology ( $\%$ coverage).

\begin{tabular}{cccc}
\hline Segment no. & $\begin{array}{c}\text { Total melt } \\
\text { pond }\end{array}$ & $\begin{array}{c}\text { Melt-pond holes } \\
\text { through pack ice }\end{array}$ & $\begin{array}{c}\text { Effective } \\
\text { melt pond }\end{array}$ \\
$\%$ & $\%$ & $\%$ \\
\hline 1 & 24 & 1.9 & 22 \\
2 & 17 & 2.6 & 14 \\
3 & 22 & 5.4 & 16 \\
All Images & $20 \pm 8$ & $3.3 \pm 3.7$ & $16 \pm 6$ \\
\hline
\end{tabular}




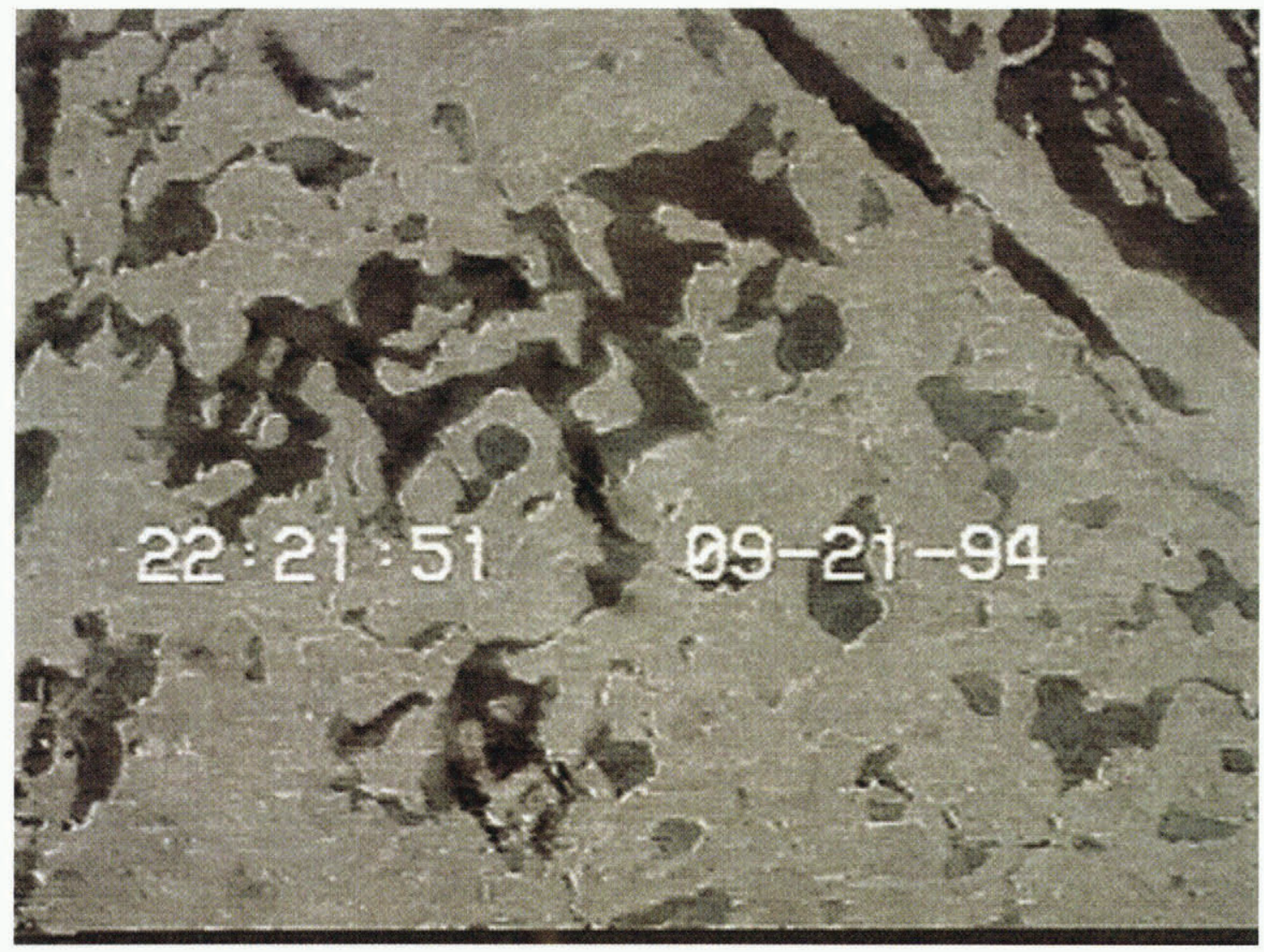

Fig. 4. Mell ponds that have penetrated through the underlying ice pack.

ice edge is approached, since the ice thins towards the edge. The effective melt-pond coverage shown in Table 3 is the remainder of the pond fraction that still exhibits the typical spectral response.
For models that simulate local conditions near the ice margin, it is recommended that the effective melt-pond coverage be used, and the frozen melt-pond hole percentage be counted along with new ice, since the spectral response is

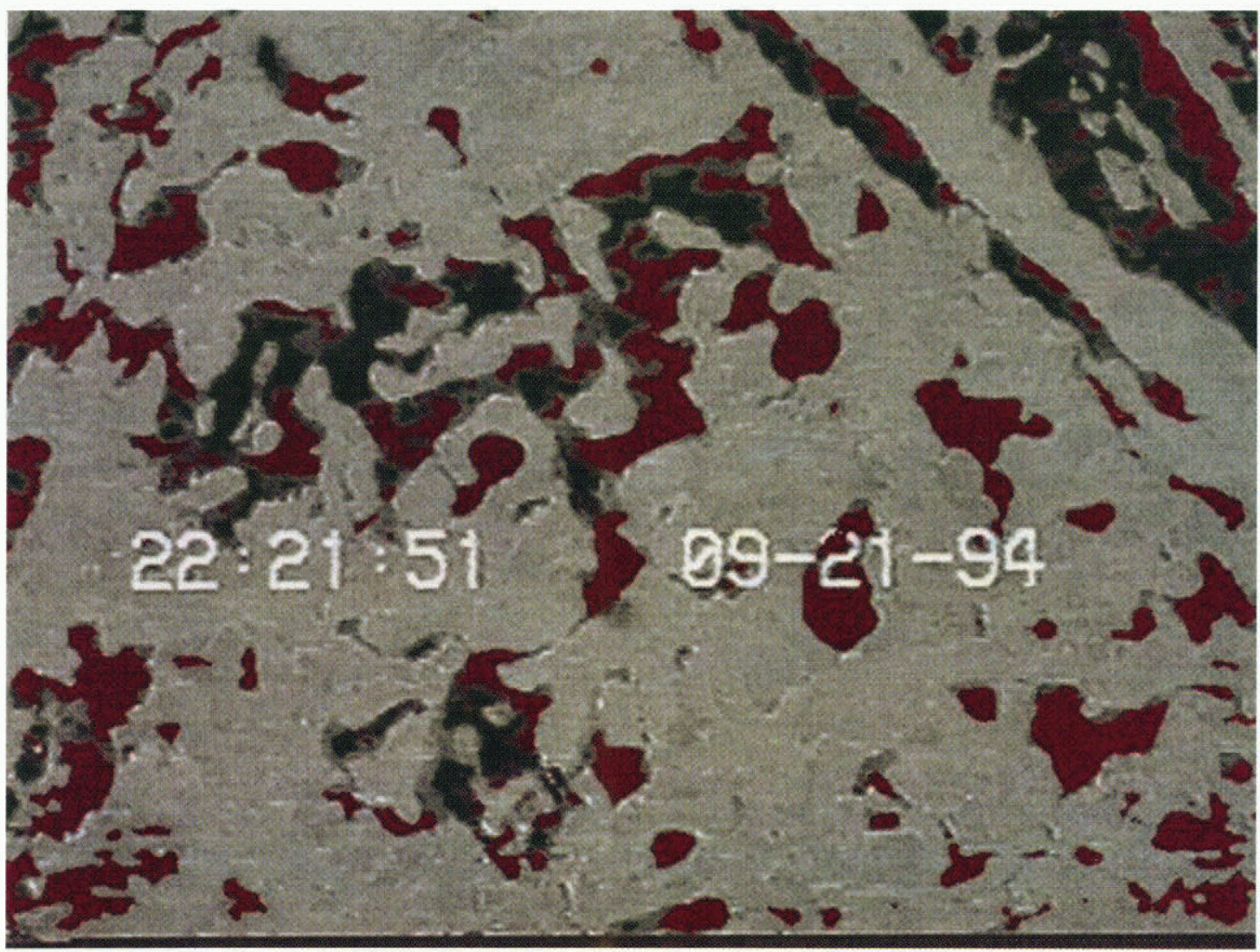

Fig. 5. Spectral identification of frozen melt ponds that have penetrated through the underlying ice pack. Holes through the pack are in green and the remainder of the pond is in red. 
similar. In this dataset, this would increase the new-ice areal percentage from 5.1 to 8.4 . The portion of the pond away from the hole, on the pond perimeter, still exhibits the spectral difference between blue and red required for the threshold identification technique, and is thus included in the effective melt-pond percentage. Some unfrozen areas within these ponds were also identified, with an areal fraction of $0.27 \%$.

As a preliminary effort to relate such measurements to sea-ice models, the observed ice conditions were compared to output from a single-column ice-thickness distribution model recently developed by Schramm and others (in press). This model includes representation of first-year ice, multi-year ice, ridged ice and leads, along with an explicit melt-pond parameterization. In their baseline simulation, which is assumed to be representative of typical Beaufort Sea conditions, melt ponds freeze over on 7 August, with $10 \%$ pond coverage at this time. In the BASE video, all ponds appeared frozen on 21 September 1994.

Frozen ponds still contribute to the lowering of the surface albedo until covered with snow, which was observed on the next BASE flight (25 September). Field measurements by Morassutti and LeDrew (1995) found the albedo of frozen ponds in the Canadian Archipelago to average 0.26, although the value is expected to be somewhat higher in September (see Perovich, 1991). The open-water lead fraction simulated by the Schramm and others (in press) model in mid-September is $0.02 \%$, compared to $0.21 \%$ in this study. However, note the relatively large standard deviation for open water of $0.43 \%$ using the video technique: this can be explained by the fact that there were many images without any open water, and few with a comparatively large amount. Clearly, these isolated measurements will differ from climatological simulations, but such comparisons illustrate the utility of high-resolution observations for model validation.

\section{GONGLUSIONS}

The spectral-identification technique is an accurate and time-saving method for identifying melt ponds, new ice and open water from low-level aircraft video images. Application of this method to the BASE video-image set from the 21 September 1994 flight resulted in a total percent areal coverage of $20 \%$ for melt ponds, $5.1 \%$ for new ice and $0.20 \%$ for open water. This technique can be easily applied to current low-altitude aircraft image datasets, and will be useful when analyzing video images obtained from future aircraft surveys.
Coverage for new ice increases as the ice edge is approached. Refreezing leads, as expected, contribute to this increase (see Table 2). Interestingly, the increasing fraction of new ice in melt ponds that have melted through the pack ice (Table 3) also contributes substantially to the newice fraction. The holes in the bottom of the ponds reduce the melt-pond coverage to an effective value of $16 \%$, and increase the areal percentage of new ice to $8.4 \%$ in the area of study.

The surface-feature areal-extent percentages found in this study are useful for evaluating large-scale sea-ice models. However, it is necessary to expand this dataset temporally and spatially with future aircraft missions. Variation in melt pond, new ice and open-water coverage with increasing latitude should be obtained with flights from lower Arctic latitudes to the North Pole. Repeated surveillance of particular sites is also necessary to observe the morphology of the surface over time.

\section{ACKNOWLEDGEMENTS}

This research was supported by NSF OPP 9504261. Comments from J. Walsh and D. Perovich were also appreciated.

\section{REFERENCES}

Allison, I., R. E. Brandt and S. G. Warren. 1993. East Antarctic sea ice: albedo, thickness distribution, and snow cover. f. Geophys. Res., 98 (C7), $12,417-12,429$.

Curry, J. A., J. O. Pinto, T. Benner and M. Tschudi. 1996. Evolution of the cloudy boundary layer during the autumnal freezing of the Beaufort Sea. 7. Geophys. Res., 102 (D12), 13,851-13,860.

De Abreu, R., D. G. Barber, K. Misurak and E. F. LeDrew. 1995. Spectral albedo of snow-covered first-year and multi-year sea ice during spring melt. Ann. Glaciol., 21,337-342.

Grenfell, T. C. and G. A. Maykut. 1977. The optical properties of ice and snow in the Arctic Basin. f. Glaciol., 18 (80), 445- 463.

Kellogg, W.W. 1975. Climatic feedback mechanisms involving the polar regions. In Weller, G. and S. A. Bowling, eds. Climate of the Arctic. Fairbanks, AK, University of Alaska. Geophysical Institute, 111-116.

Lapp, D. 1982. Study on ice meltponds. Toronto, Ont., Polar Research and Engineering for Atmospheric Environment Service. (Contract report.)

Morassutti, M. P. and E. F. LeDrew. 1995. Melt pond dataset for use in sea-ice and climate-related studies. Waterloo, Ont., University of Waterloo. Institute for Space and Terrestrial Science. Earth-Observations Laboratory. (Tech. Rep. Ser. ISTS-EOL-TR95-001.)

Perovich, D. K. 1991. Seasonal changes in sea ice optical properties during fall freeze-up. Cold Reg. Sci. Technol., 19(3), 261-273.

Perovich, D. K., G. A. Maykut and T. C. Grenfell. 1986. Optical properties of ice and snow in the polar oceans. I: Observations. SPIE J., 637, 232-244.

Schramm, J. L., M. M. Holland and J. A. Curry. In press. Modeling the thermodynamics of a distribution of sea ice thicknesses. Part I. Model description and validation. J. Geophys. Res. 